\title{
The Odense Androgen Study
}

Torben Leo Nielsen, Kim Brixen, Anne Pernille Hermann, Marianne Andersen Dept. of Endocrinology, Odense University Hospital, University of Southern Denmark

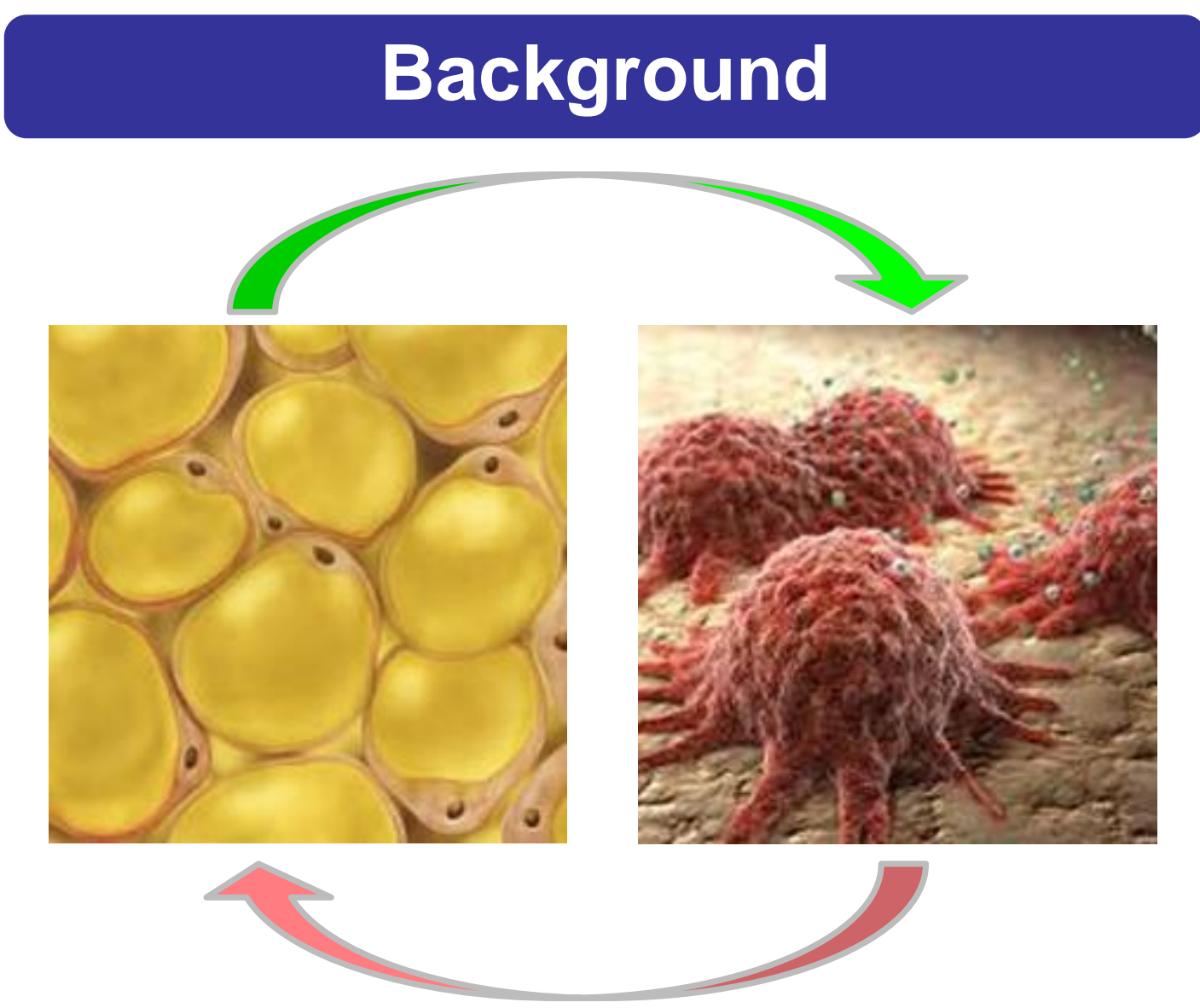

Adipocytes affect bone (leptin, neuronal pathways)

Karsenty et al. Cell Metab. 2006

Thus (by principle of feed back loops)

Bone must affect adipocytes

Lee et al, Cell. 2007 \& Kindlblom et al, JBMR. 2009

\section{Objectives}

To examine the relationship between osteocalcin and regional fat depots

\section{Results}

Osteocalcin vs. BMI, waist, and fat mass
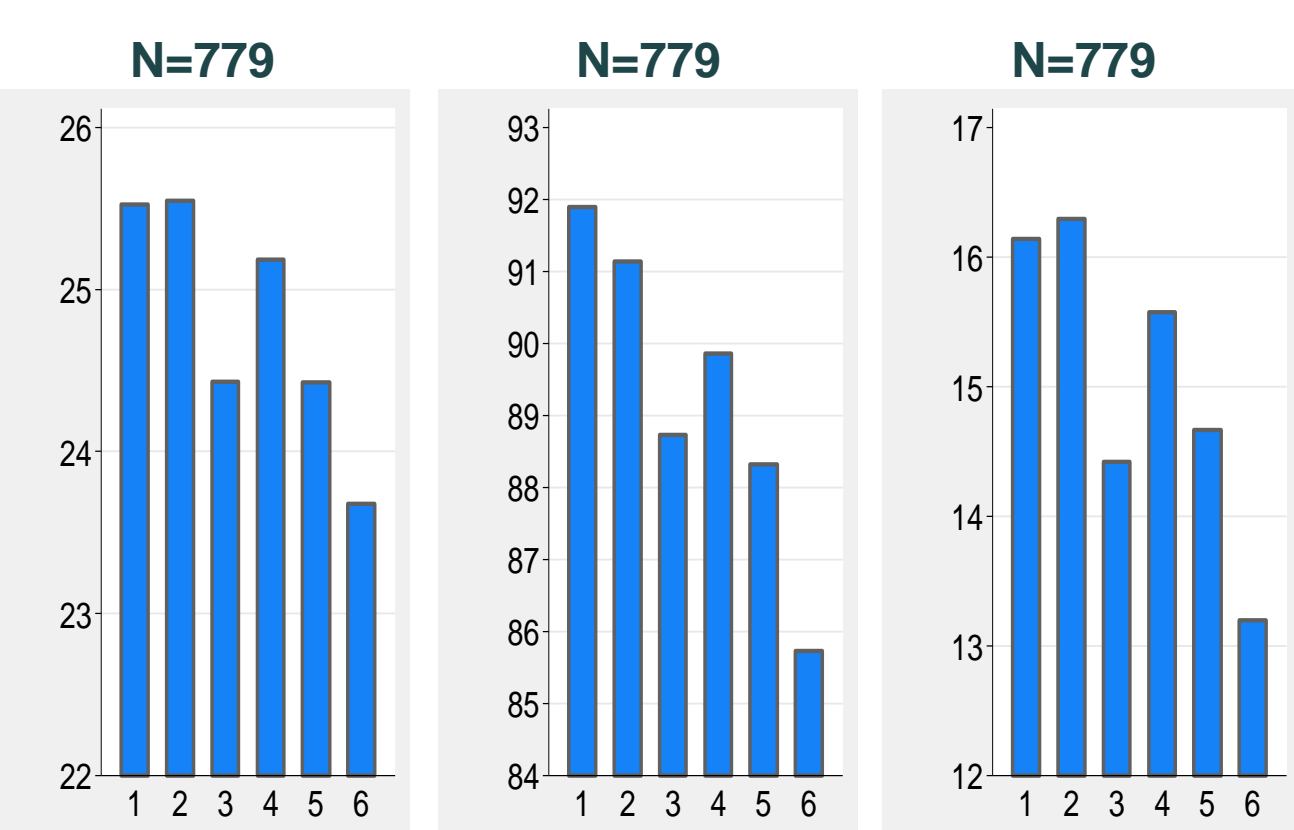

$R=-0.19, p<0.0001$

$R=-0.21, p<0.0001$

$R=-0.18, p<0.0001$

OSTEOCALCIN IN SIXTILES ON X-SCALE

All bone markers vs. waist
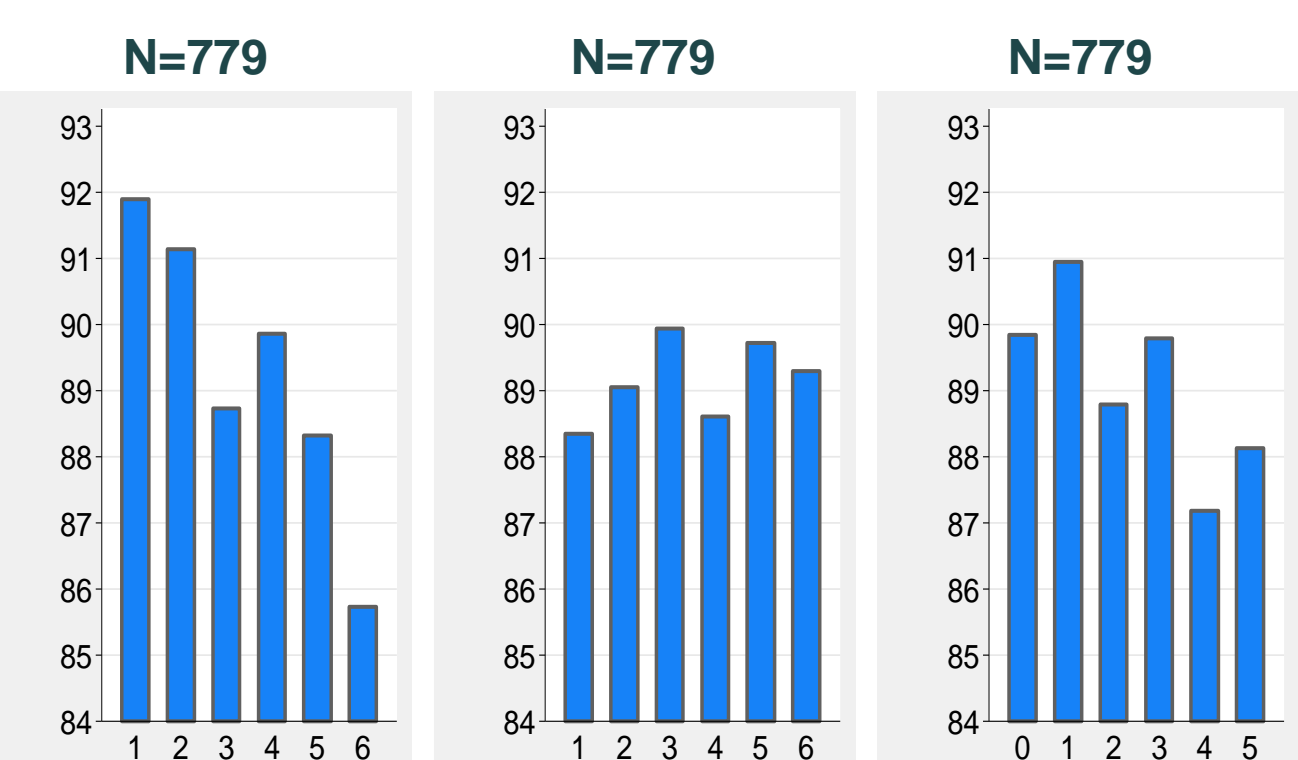

$\mathbf{R}=-\mathbf{0 . 2 1}, \mathrm{p}<0.0001$

$R=-0.03, N S$

$R=-0.05, N S$

OSTEOCALCIN

1CTP
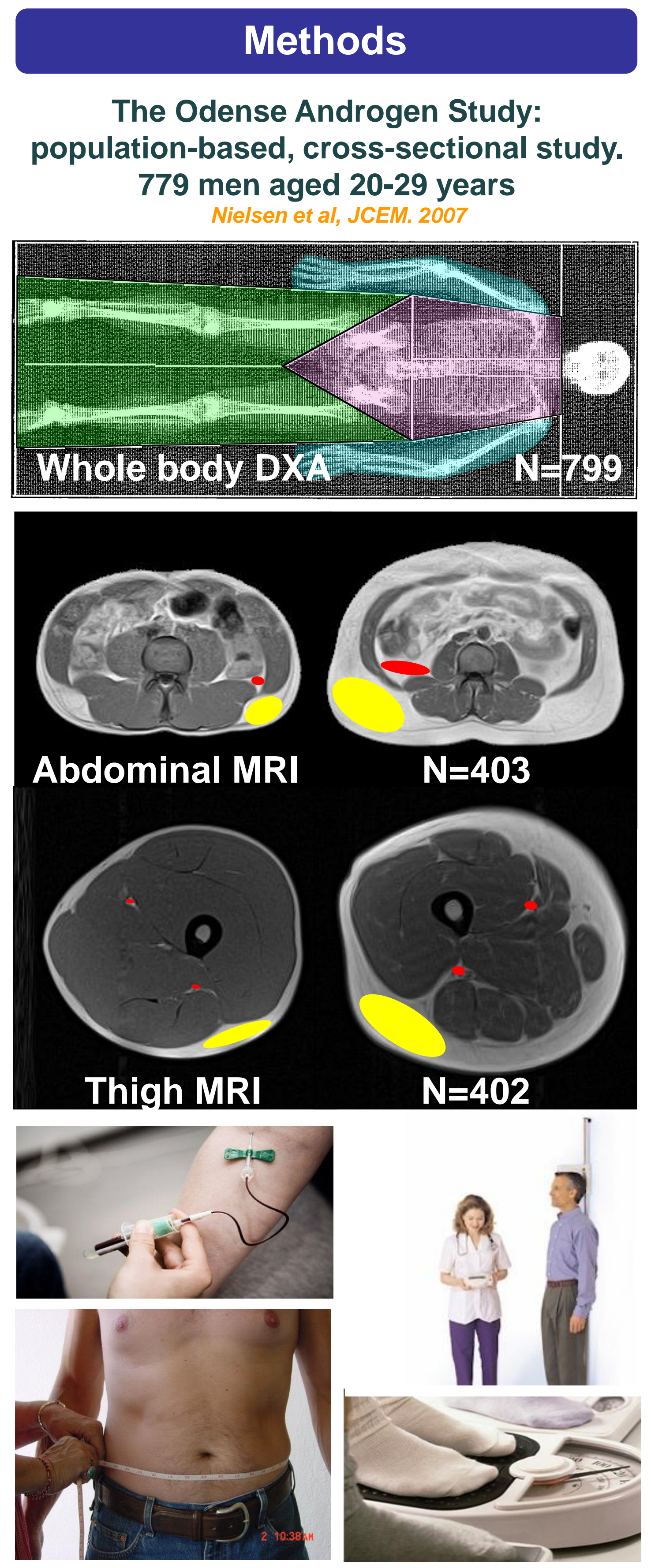

\section{Results}

Osteocalcin vs. bs-ALP and 1CTP
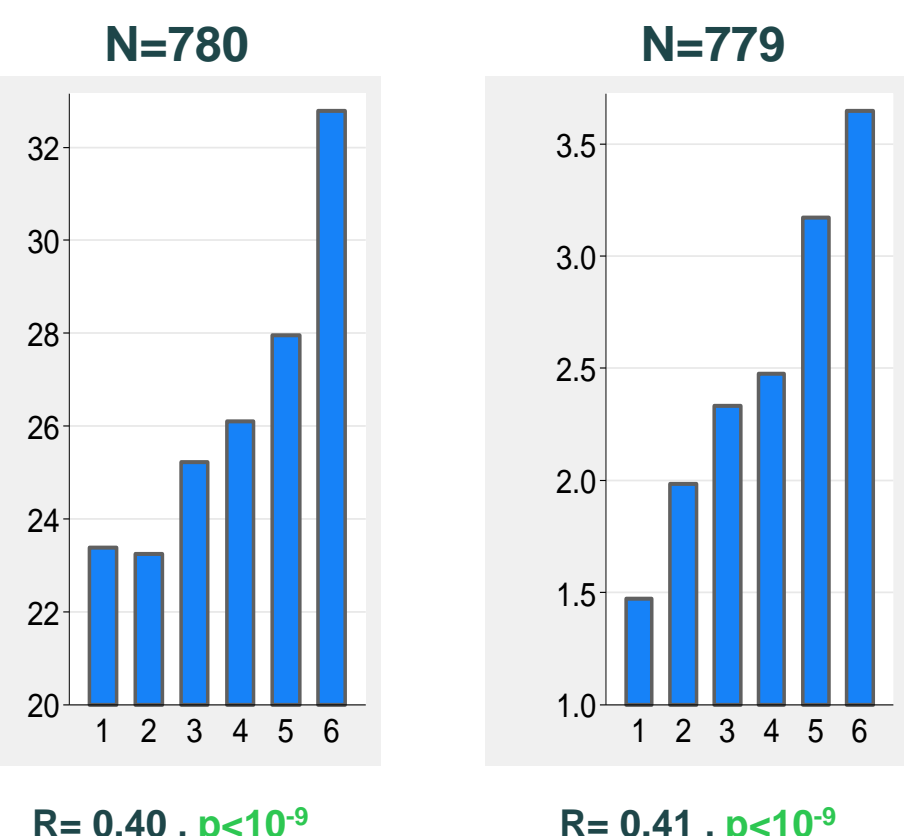

OSTEOCALCIN IN SIXTILES ON X-SCALE

\section{Results}

DXA fat parameters - adjusted
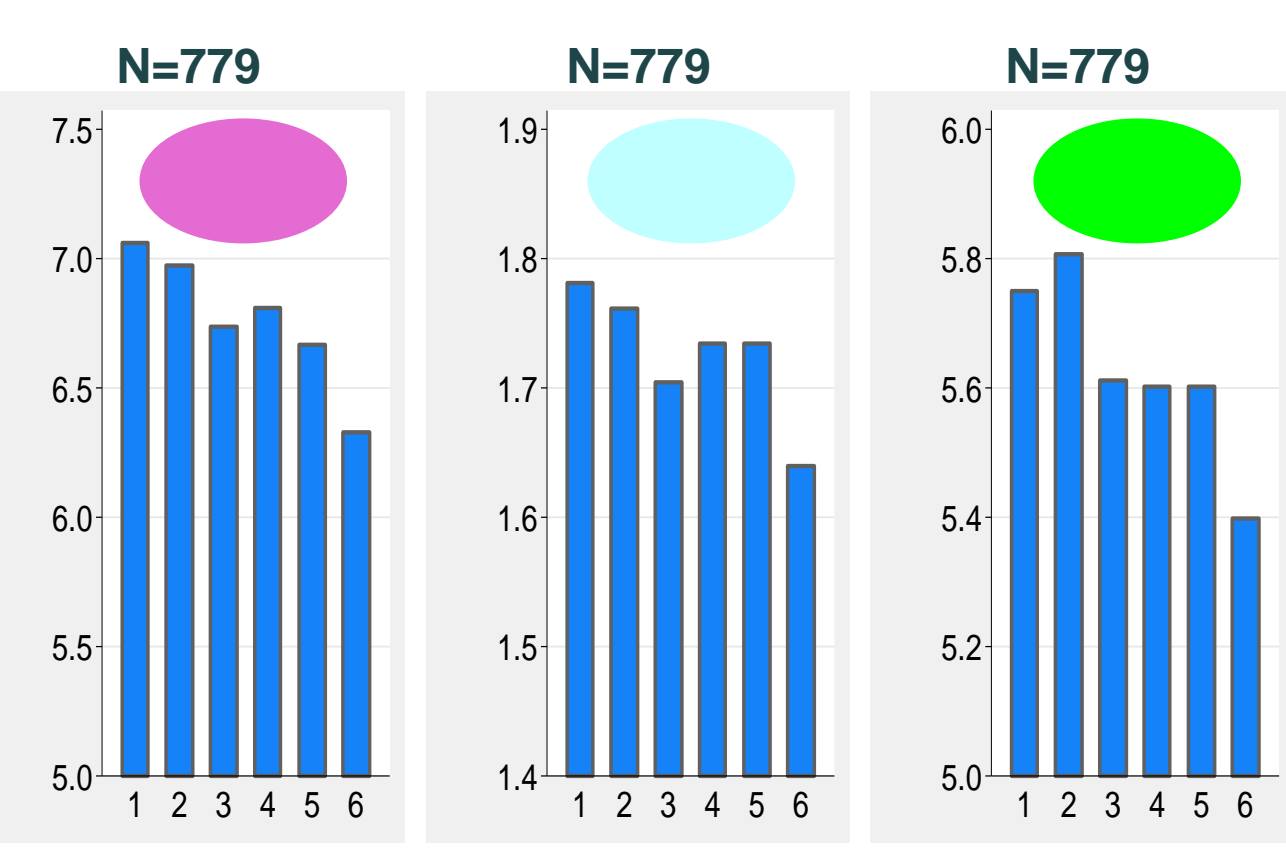

$R=-0.12, p=0.00$

$R=-0.09$, NS

$R=-0.09, \mathrm{NS}$

OSTEOCALCIN IN SIXTILES ON X-SCALE

MRI fat parameters - adjusted

Abdominal MR

Thigh MRI

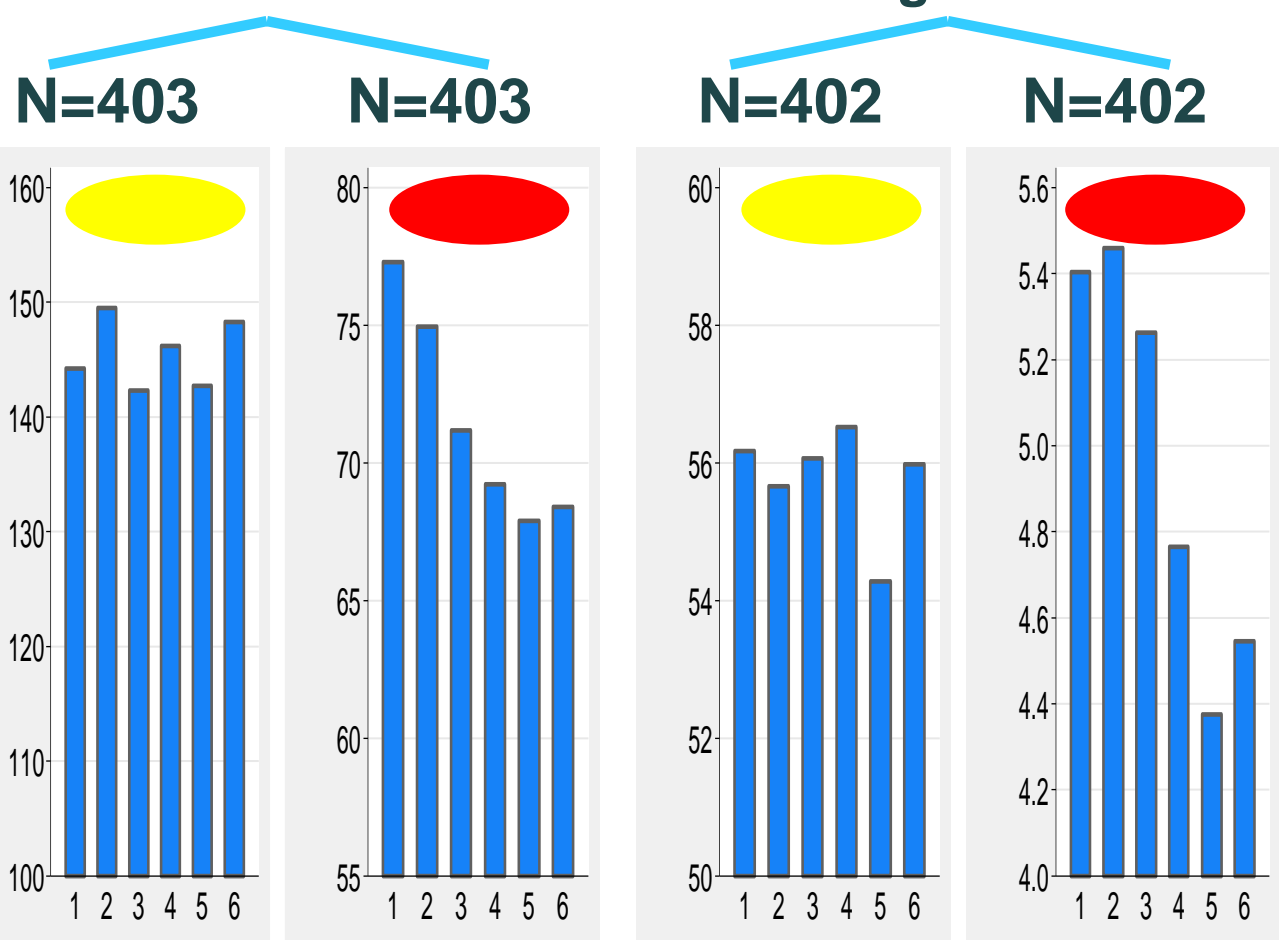

$R=0.02$, NS $\quad R=-0.19, p<0.001 \quad R=-0.002$, NS $\quad R=-0.16, p=0.001$

OSTEOCALCIN IN SIXTILES ON X-SCALE

\section{Conclusions}

Associations: central fat vs. peripheral fat

DXA:

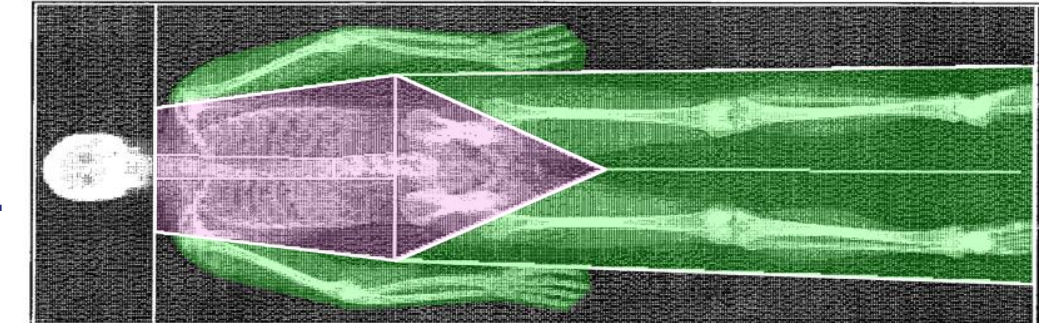

Associations: deep vs.

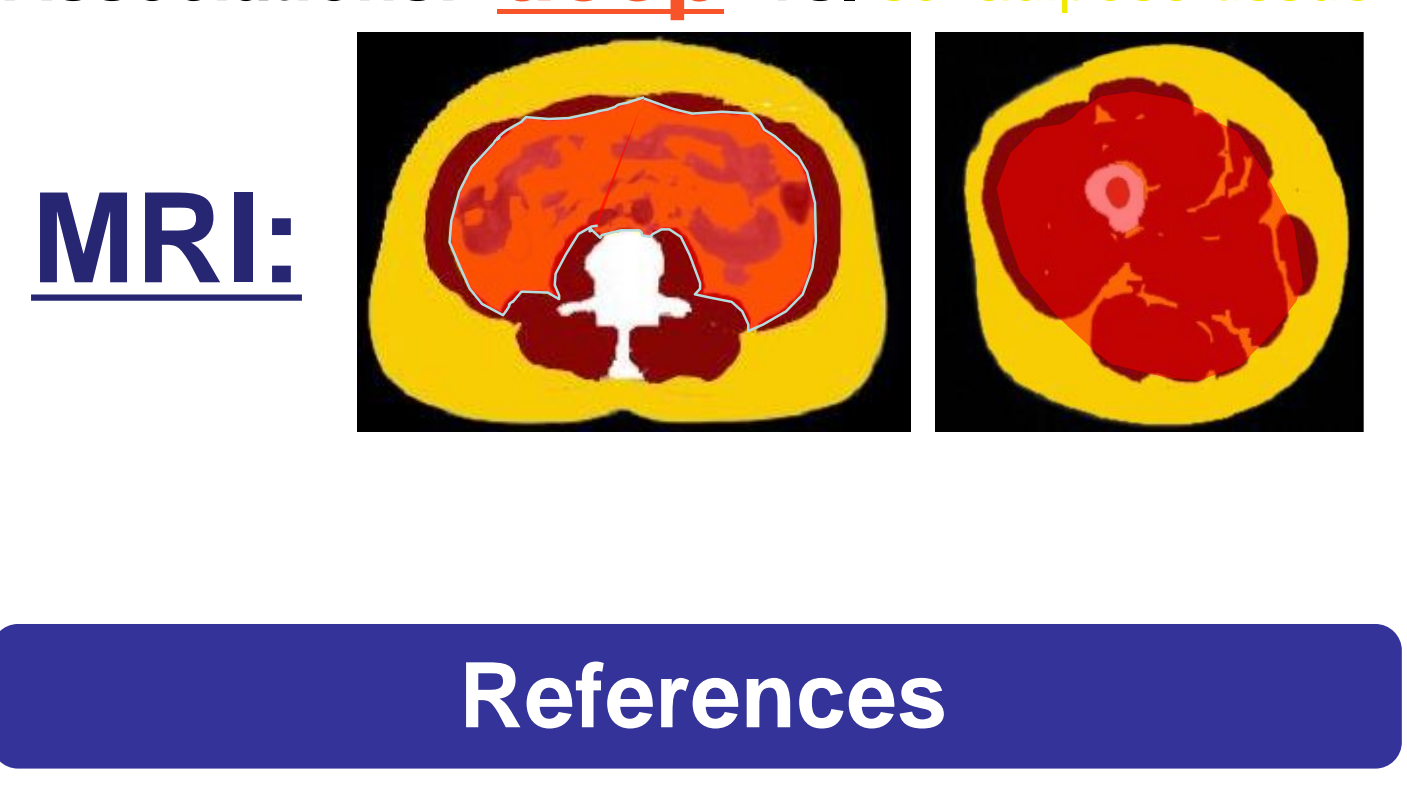

1. Karsenty et al, Cell Metab. 2006

2. Lee et al, Cell. 2007

3. Kindblom et al, JBMR. 2009 